\title{
KOMUNIKASI EFEKTIF DALAM KOLABORASI INTERPERSONAL SEBAGAI UPAYA UNTUK MENINGKATKAN PELAYANAN KESELAMATAN PASIEN YANG BERMUTU
}

Ade sulistya lubis/181101121

adesulistyalubis@gmail.cun

\begin{abstract}
Abstrak
Latar belakang: Kualitas pelayanan yang diberikan oleh pihak rumah sakit cenderung dilihat atau dinilai oleh pasien atau masyarakat pengguna terutama di ruang rawat inap. Tujuan : agar dapat mengetahui komunikasi efektif dalam kolaborasi interpersonal sebagai upaya untuk meningkatkan pelayanan keselamatan pasien yang bermutu.Metode: menggunakan metode tersearch dan analisis dari fasilitas kesehatan tersebut dari bentuk pelayanan yang diberikan oleh perawat dan dokter berbagai sumber seperti buku teks, buku referensi jurnal, e-book, dan juga membandingkan beberapa jurnal yang berhubungan komunikasi efektif dalam kolaborasi interpersonal sebagai upaya untuk meningkatkan pelayanan keselamatan pasien yang bermutu. Hasil: Berhasilnya suatu komunikasi adalah apabila kita mengetahui dan mempelajari unsur-unsur yang terkandung dalam proses komunikasi untuk peningkatan pelayanan keselamatan pasien yang bermutu. Kesimpulan: Komunikasi efektif dalam Interprofesi Collaboration Practice sebagai upaya meningkatkan kualitas pelayan.
\end{abstract}

Kata kunci: komunikasi efektif, kolaborasi interpersonal, keselamat pasien

Abstract

Background: The quality of services provided by the hospital tends to be seen or valued by patients or the user community, especially in the inpatient room. Objective: to be able to find out effective communication in interpersonal collaboration as an effort to improve quality patient safety services. Method: use the search method and analysis of the health facility from the form of services provided by nurses and doctors various sources such as textbooks, journal reference books, e-books, and also comparing several journals related to effective communication in interpersonal collaboration in an effort to improve quality patient safety services. Results: The success of a communication is if we know and learn the elements contained in the communication process to improve quality patient safety services. Conclusion: Effective communication in Interprofessional Collaboration Practice as an effort to improve the quality of service.

Keywords: effective communication, interpersonal collaboration, patient safety 
PENDAHULUAN

\section{LATAR BELAKANG}

Pelayanan yang ada di rumah sakit merupakan pelayanan yang multidisilpin sehinga bisa berpotensi terjadinya pelayanan yang tumpang tindih, terjadinya konflik interprofesional dan juga keterlambatan pemeriksaan dan tindakan (Susilaningsih, 2016). Dalam pelayanan kesehatan terjadi kesalahan (error) 70-80 $\%$ yang disebabkan oleh buruknya komunikasi dan pemahaman dalam tim, kerjasama tim yang baik dapat membantu mengurangi masalah patient safety (WHO, 2009).

Upaya peningkatan kualitas pelayanan tersebut diperlukan keselarasan langkah yang dinamis antar berbagai klinisi dan disiplin keilmuan untuk membangun tim pelayanan dengan tatanan dan kultur pendekatan interdisiplin atau interprofesional. Pasien yang ditangani secara interdisiplin baik di ruang rawat inap maupun pelayanan kesehatan primer, meningkatkan kesinambungan asuhan, kepuasan pasien serta mengurangi hospitalisasi dan angka kematian (Mitchell\&Crittenden,2000)

Kolaborasi interprofesional merupakan merupakan strategi untuk mencapai kualitas hasil yang dinginkan secara efektif dan efisien dalam pelayanan kesehatan. Komunikasi dalam kolaborasi merupakan unsur penting untuk meningkatkan kualitas perawatan dan keselamatan pasien (Reni,A al,2010). Kemampuan untuk bekerja dengan profesional dari disiplin lain untuk memberikan kolaboratif, patient centred care dianggap sebagai elemen penting dari praktek profesional yang membutuhkan spesifik perangkat kompetensi.

The American Nurses Association (ANA, 2010) menggambarkan komunikasi efektif sebagai standar praktik keperawatan profesional. Kompetensi profesional dalam praktek keperawatan tidak hanya psikomotor dan keterampilan diagnostik klinis, tetapi juga kemampuan dalam keterampilan interpersonal dan komunikasi. Perawat terdaftar diharapkan untuk berkomunikasi dalam berbagai format dan di semua bidang praktek. 


\section{TUJUAN}

Tujuan pembandigan dari beberapa jurnal dan sumber lainnya agar dapat mengetahui bagaimana Komunikasi efektif dalam kolaborasi interpersonal sebagai upaya untuk meningkatkan pelayanan keselamatan pasien yang bermutu.

\section{METODE}

Jurnal ini menggunakan metode tersearch dan analisis dari berbagai sumber seperti buku teks, buku referensi jurnal, e-book, dan juga membandingkan beberapa jurnal yang berhubungan dengan Komunikasi efektif dalam kolaborasi interpersonal sebagai upaya untuk meningkatkan pelayanan keselamatan pasien yang bermutu. Dari analisi berbagai sumber digunakan Untuk mengetahui komunikasi efektif dalam kolaborasi interpersonal sebagai upaya untuk meningkatkan pelayanan keselamatan pasien yang bermutu. Penulisan jurnal ini dimulai pada tanggal 30 oktober 2019. Pengolahan jurnal dilakukan dengan metode membandingkan beberapa jurnal yang berhubungan komunikasi efektif dalam kolaborasi interpersonal sebagai upaya untuk meningkatkan pelayanan keselamatan pasien yang bermutu.

\section{HASIL}

Dari jurnal (Rokhmah, Noor Ariyani Anggorowati. 2017. komunikasi efektif dalam praktek kolaborasi interprofesi sebagai upaya meningkatkan kualitas pelayanan: Journal of Health Studies, Vol. 1, No.1) Berhasilnya suatu komunikasi adalah apabila kita mengetahui dan mempelajari unsur-unsur yang terkandung dalam proses komunikasi. Unsur-unsur itu adalah sumber (resource), pesan (message), saluran (channel/ media) dan penerima (receiver/audience). Komunikasi dapat efektif apabila pesan diterima dan dimengerti sebagaimana dimaksud oleh pengirim pesan, pesan ditindaklanjuti dengan sebuah perbuatan oleh penerima pesan dan tidak ada hambatan untuk hal itu (Hardjana, 2003).

$$
\begin{aligned}
& \text { Komunikasi yang efektif terjadi bila } \\
& \text { pendengar (penerima berita) menangkap } \\
& \text { dan menginterpretasikan ide yang } \\
& \text { disampaikan dengan tepat seperti apa yang } \\
& \text { dimaksud oleh pembicara (pengirim } \\
& \text { berita). Terdapat beberapa faktor yang }
\end{aligned}
$$


perlu diperhatikan untuk mengupayakan proses komunikasi yang efektif, yaitu antara lain:

\section{Sensitifitas kepada penerima komunikasi}

Sensitivitas ini sangatlah penting dalam penentuan cara komunikasi serta pemilihan media komunikasi. Hal-hal yang bersifat penting dan pribadi paling baik dibicarakan secara langsung atau tatap muka, dan dengan demikian mengurangi adanya kecanggungan serta kemungkinan adanya miskomunikasi. Kesadaran dan pengertian terhadap makna simbolis

Hal ini menjadi penting dalam seseorang mengerti komunikasi yang disampaikan. Komunikasi seringkali disampaikan secara non verbal atau lebih dikenal dengan body language. Pengertian akan body language, yang bisa berbeda sesuai dengan kultur, ini akan memberikan kelebihan dalam komunikasi.

Penentuan waktu yang tepat dan umpan balik

Hal ini sangatlah penting terutama dalam mengkomunikasikan keadaan yang bersifat sensitif. Umpan balik menjadikan komunikasi lebih efektif karena dapat memberikan kepastian mengenai sejauh mana komunikasi yang diadakan oleh seseorang sumber (source) dapat diterima oleh komunikan (receiver).

\section{Komunikasi tatap muka}

Komunikasi semacam ini memungkinkan kita untuk melihat dengan baik lawan bicara kita, melihat body language, melihat mimik lawan bicara, serta menghilangkan panjangnya rantai komunikasi yang memungkinkan terjadinya mis komunikasi.

\section{Komunikasi efektif}

Komunikasi efektif diharapkan dapat mengatasi kendala yang ditimbulkan oleh beberapa pihak, pasien, dokter, perawat maupun tenaga kesehatan lainnya. Dokter dapat mengetahui dengan balk kondisi pasien dan keluarganya dan pasien pun percaya sepenuhnya kepada dokter. Kondisi ini amat berpengaruh pada proses penyembuhan pasien selanjutnya. Literature review ini bertujuan untuk bertujuan untuk mengetahui efektifitas komunikasi efektif dalam praktik kolaborasi interprofesi akan meningkatkan kualitas pelayanan.

\section{PEMBAHASAN}

Dari jurnal (Rokhmah, Noor Ariyani Anggorowati. 2017. komunikasi efektif 
dalam praktek kolaborasi interprofesi sebagai upaya meningkatkan kualitas pelayanan: Journal of Health Studies, Vol. 1, No.1) Rumah sakit adalah organisasi dalam bidang jasa pelayanan kesehatan .Dalam penyelenggaraan upaya pelayanan pada pasien rumah sakit didukung oleh banyak jenis ketrampilan SDM baik yang berbentuk profesi maupun non profesi. Rumah Sakit yang bermutu adalah rumah sakit yang memberikan pelayanan melalui penyelenggaraan pelayanan secara paripurna pada unit unit gawat darurat, rawat jalan, rawat inap, ruang tindakan dan ruang perawatan khusus.

Penyelenggaraan pelayanan dilaksanakan oleh berbagai kelompok profesi. Para profesional utama yang memberikan asuhan kepada pasien di rumah sakit adalah staf medis baik dokter maupun dokter spesialis, staf klinis keperawatan (perawat dan bidan), nutrisionis dan farmasis yang rutin dan pasti selalu berkontak dengan pasien, akan tetapi tidak kalah pentingnya profesional lain yang berfungsi melakukan asuhan penunjang berupa analis laboratorium, penata rontgen, fisioterapis. Penyediaan pelayanan yang paling sesuai di suatu rumah sakit untuk mendukung dan merespon setiap kebutuhan pasien yang unik, memerlukan perencanaan dan koordinasi tingkat tinggi.

Pelayanan yang ada di rumah sakit merupakan pelayanan yang multidisilpin sehinga bisa berpotensi terjadinya pelayanan yang tumpang tindih, terjadinya konflik interprofesional dan juga keterlambatan pemeriksaan dan tindakan (Susilaningsih, 2016). Dalam pelayanan kesehatan terjadi kesalahan (error) 70-80 $\%$ yang disebabkan oleh buruknya komunikasi dan pemahaman dalam tim, kerjasama tim yang baik dapat membantu mengurangi masalah patient safety (WHO, 2009) Upaya peningkatan kualitas pelayanan tersebut diperlukan keselarasan langkah yang dinamis antar berbagai klinisi dan disiplin keilmuan untuk membangun tim pelayanan dengan tatanan dan kultur pendekatan interdisiplin atau interprofesional. Pasien yang ditangani secara interdisiplin baik di ruang rawat inap maupun pelayanan kesehatan primer, meningkatkan kesinambungan asuhan, kepuasan pasien serta mengurangi hospitalisasi dan angka kematian (Mitchell\&Crittenden,2000) 
Anggarawati, Tuti, Wulan Sari, N, 2016.

\section{KESIMPULAN}

Komunikasi efektif dalam Interprofesi Collaboration Practice sebagai upaya meningkatkan kualitas pelayan. Oleh karena itu, komunikasi yang efektif dan kolaborasi perlu diberi penekanan yang kuat di semua program perawatan kesehatan profesional untuk menjamin kepuasan dan keamanan pasien.

\section{SARAN}

Komunikasi yang efektif dan kolaborasi perlu diberi penekanan yang kuat di semua program perawatan kesehatan profesional untuk menjamin kepuasan dan keamanan pasien.

\section{REFERENSI}

Agus M Hardjana. 2003. Komunikasi

Interpersonal dan

Intrapersonal. Yogyakarta :

Kanisius.

Anita Davis Boykins. 2014. DNSc, FNP-

$\mathrm{BC}, \mathrm{PMHNP} \mathrm{BC}$, Core

Communication

Competencies in Patient-

Centered Care. The ABNF

Journal/Spring.
Kepentingan Bersama

Perawat - Dokter dengan

Kualitas Pelayanan

Keperawatan: Jurnal Ilmiah

Kesehatan Keperawatan. Vol.

12, No. 1. Februari.

Arya Reni, Kurniawan Yudianto, Irman

Somantri. 2010. Efektifitas

Pelaksanaan Komunikasi dalam

Kolaborasi Antara Perawat dan

Dokter di Ruang Rawat Inap

Rumah Sakit Umum Sumedang.

Jurnal unpad.ac.id/mku/article.

Vol. 12, No. 1.

Diane Morris, Mscfn, RD, CDE, Matthews, Phd, RD, Phec. 2014.

Communication, Respect, and Leadership: InterprofessionalCollaboratio

$\mathrm{n}$ in Hospitals of Rural Ontario. Canadian Journal of Dietetic Practice and Research. Vol 75, No 4.

Esther Suter, Julia Arndt, Nancy Arthur, John Parboosingh, Elizabeth Taylor, \& Siegrid Deutschlander. 2009. Role Understanding and Effective Communication as Core Competencies

For 
Collaborative Practice.

Journal of Interprofessional

Care, Informa Healthcare. Vol (no) : 23(1): pp 41-51.

January 2009.

Matziou1, V, Vlahioti, E, Pantelis Perdikaris, Theodora Matziou, Efstathia Megapanou and Konstantinos Petsios. 2014. Physician and nursing perceptions concerning interprofessional

Communication and collaboration. Journal of Interprofessional Care. Vol (no) : 28(6): pp 526-533.

Mitchell,PH, Crittenden, RA. 2000. Interdiciplinarry

Collaboration : old ideas with new urgency. Washington Publik Health Organization.

Orchad, CA, Curran , V, Kabene, S. 2005. Creating a culture for Interdiciplinnary Collabiration Profesional

Practice. Med. Educ WHO. 2010. Framework for Action on Interprofesional Education \& Collaborative Practice.
Geneva : World Health Organization.

Rokhmah, Noor ,Ariyani Anggorowati. 2017. komunikasi efektif dalam praktek kolaborasi interprofesi sebagai upaya meningkatkan kualitas pelayanan: Journal of Health Studies, Vol. 1, No.1

R.H.Simamora (2019). Buku ajar pelaksanaaan indentifikasi pasien. Uwais Inspirasi indonesi R.H. Simamora. (2019). The infiuence of Training handover based SBAR Communication for Improving patients safety. Indian journal of public heath research \& Deveopment

R.H. Simamora (2019). Documentation of Patient Identifikasi Into the hectronic system to improve the quality of nursing serviceec International) journal of soenrifio \& technology tesearch 